\title{
Associations between arterial stiffness and cardiovascular disease risk factors among black South African children
}

\author{
A van Biljon, $\mathrm{PhD}$; H Erasmus, $\mathrm{PhD} ; \mathrm{M}$ L Mathunjwa, $\mathrm{PhD}$ \\ Department of Human Movement Science, Faculty of Science and Agriculture, University of Zululand, KwaDlangezwa, South Africa
}

Corresponding author: A van Biljon (vanbiljona@unizulu.ac.za)

\begin{abstract}
Background. A limited number of studies have researched the associations between conventional cardiovascular disease (CVD) risk factors and arterial stiffness in children.

Objectives. To explore the associations between specific conventional CVD risk factors and arterial stiffness in black South African (SA) children.

Methods. This cross-sectional study included 59 children (male:17; female:42). The mean age (and associated standard deviation) of the participants was 11.15 (1.40) years. Conventional CVD risk factors included body mass index (BMI), waist circumference (WC), hip circumference, systolic blood pressure (SBP), resting heart rate (RHR), peak oxygen consumption $\left(\mathrm{VO}_{2}\right.$ peak) and physical activity. Pearson's correlation was used to measure associations between arterial stiffness, expressed as the stiffness index (SI), and CVD risk factors. Hierarchical multiple regression analysis adjusting for age was performed to identify associations between the independent variables ( $\mathrm{VO}_{2}$ peak, SBP, BMI, physical activity, RHR and WC) and the dependent variable (SI).

Results. Arterial stiffness was found to be significantly positively correlated with age $(r=0.52 ; p=0.03)$ and significantly negatively correlated with $\mathrm{VO}_{2}$ peak $(r=-0.53 ; p=0.03)$ in male participants. Following regression analysis, the association with age $\left(r^{2}=0.27 ; p=0.03\right)$ and SI remained significantly independent. When means were combined across the two gender groups, age $(r=0.27 ; p=0.04)$ and RHR $(r=0.26 ; p=0.05)$ were found to be significantly positively correlated with SI. Following regression analysis, both age $\left(r^{2}=0.07 ; p=0.04\right)$ and RHR $\left(r^{2}=0.15 ; p=0.02\right)$ remained significantly independently associated with SI.

Conclusion. Age and RHR appear to be strong predictors of arterial stiffness in black SA children.
\end{abstract}

S Afr J Child Health 2021;15(1):14-17. https://doi.org/10.7196/SAJCH.2021.v15i1.1743

Cardiovascular disease (CVD) is the leading cause of mortality and morbidity worldwide and is estimated to cause 17.3 million deaths per year. ${ }^{[1]}$ CVD incidence is strongly associated with a set of conventional risk factors, which include increased waist circumference (WC), high body mass index (BMI), high systolic blood pressure (SBP), increased levels of low-density lipoprotein, high blood glucose levels, low levels of physical activity and poor cardiorespiratory fitness. ${ }^{[2]}$

However, screening for these conventional risk factors may underestimate the risk of CVD, especially in asymptomatic children. ${ }^{[3]}$ Therefore, other non-conventional risk factors may be important to consider. Pulse wave velocity can be used as an indicator of arterial stiffness, which suggests structural changes in arterial walls that precede the events of atherosclerosis and CVD. ${ }^{[4]}$ Arterial stiffness has been reported to be a notable risk factor for developing future CVD independent of conventional risk factors in adults. ${ }^{[4]}$ Similarly, arterial stiffness has been shown to be positively associated with several conventional risk factors for CVD in children, ${ }^{[5]}$ although findings in paediatric studies are inconsistent.

Reed et al. ${ }^{[6]}$ determined the predictors of arterial stiffness in a sample of 99 Canadian children (aged 9 - 11 years). The results showed that children in the highest fitness quartile had $34 \%$ greater arterial compliance than children in the lower quartiles. Other predictors of arterial stiffness included body mass, SBP and maturation, ${ }^{[6]}$ in accordance with a US population-based study that found significant associations between arterial stiffness, age, gender, BMI and SBP among 343 healthy adolescents and young adults (aged $15-28$ years). ${ }^{[7]}$ Conflicting results were reported in a European study, which found no significant correlations between arterial stiffness, gender, age, BMI, Tanner stage or SBP levels among 38 non-obese adolescents (mean age and associated standard deviation (SD): 15.02 (1.94) years). ${ }^{[8]}$ The same study reported a significant association between arterial stiffness and SBP among 68 obese adolescents (mean (SD) age: 13.27 (2.31) years) ${ }^{[8]}$ This could imply that early vascular damage is more apparent in obese adolescents than in their lean counterparts.

A greater understanding of arterial stiffness and its association with conventional CVD risk factors is warranted. Furthermore, it has been reported that black South African (SA) children are at an increased risk of developing CVD. ${ }^{[9]}$ Similarly, increased arterial stiffness has been reported in black SA boys (aged $6-8$ years) compared with their white counterparts. ${ }^{[10]}$ Thus, this study aimed to explore associations between specific conventional CVD risk factors and arterial stiffness in black SA children.

\section{Methods \\ Participants}

This cross-sectional study recruited 59 black SA children (17 male, 42 female) from an urban primary school in the province of KwaZulu-Natal, SA, in June 2015. The mean (SD) age of participants was 11.15 (1.40) years. The inclusion criteria specified that black children between the ages of 10 and 13 years and who 
were healthy, without any known medical conditions, were eligible for participation in the study.

\section{Measurements}

Measurements were taken on five consecutive days between 09:00 and 12:00 in a quiet room at the school. Conventional CVD risk factor measurements included BMI, WC, hip circumference, SBP, resting heart rate (RHR) and peak oxygen consumption $\left(\mathrm{VO}_{2}\right.$ peak). Participation in physical activity was also included as an associated factor and was measured according to a modified version of the self-administered physical activity questionnaire for older children (PAQ-C). ${ }^{[1]}$ The questionnaire measures general physical activity levels in children aged 8 - 14 years during a typical week in a school year. The questionnaire includes nine questions based on a broad spectrum of activities taking place during physical education, first and second breaks, days and evenings, and over the weekend. Question 1 was adapted somewhat in that some sport activities (cross-country skiing, ice hockey and badminton) included in the original questionnaire were replaced with sport activities more suitable to the SA context (cricket, athletics and rugby). All nine questions were scored on a 5-point Likert scale assessing frequency and intensity of activities. Participants were categorised as having low, moderate or high physical activity based on their final mean score. A score of $1.00-2.33$ indicated low physical activity, a score of 2.34 - 3.66 was taken as a moderate physical activity level, and a high level of physical activity was taken as a score between 3.67 and $5.00 .^{[11]}$

WC was measured midway between the lowest rib and the iliac crest in a standing position using a measuring tape.$^{[12]}$ A digital scale (OMRON Healthcare, SA) was used to measure body weight, recorded to the nearest $0.1 \mathrm{~kg}$. A portable stadiometer (Alturaexata, Brazil) was used to measure height, recorded to the nearest $0.1 \mathrm{~cm}$. BMI was calculated as body weight divided by height squared $\left(\mathrm{kg} / \mathrm{m}^{2}\right)$, and BMI $z$-scores were based on the Centers for Disease Control and Prevention standards. ${ }^{[13]}$ SBP and RHR were measured three times in a seated position using a digital automated blood pressure device (Connex ProBPTM 3400., USA) after 5 minutes of resting. The average of the second and third readings was analysed for both SBP and RHR. SBP $z$-scores were subsequently calculated according to the National Heart, Lung and Blood Institute standards. ${ }^{[14]}$ $\mathrm{VO}_{2}$ peak was estimated using the 20 -metre shuttle run test. ${ }^{[15]}$ Léger and Lambert's ${ }^{[16]}$ equation $\left(\mathrm{VO}_{2}\right.$ peak $=31.025+(3.238 \times$ velocity $)-$ $(3.248 \times$ age $)+(0.1536 \times$ age $\times$ velocity $))$ was used to obtain indirect $\mathrm{VO}_{2}$ peak values. The arterial stiffness index (SI), an indicator of large artery stiffness, was derived from digital volume pulse using the PulseTrace PCA2 photoplethysmographic device (Micro Medical,
UK). This device has also been used in other paediatric studies and has been validated by comparing results with carotid-femoral pulse wave velocity, the gold standard for measuring arterial stiffness. ${ }^{[17,18]}$ The average of two SI measurements was calculated and expressed in metres per second. Participants were tested while lying supine.

\section{Statistical analysis}

Statistical analyses were performed using SPSS for Windows (version 20.0, IBM Corp., USA). Normally distributed data were expressed as means and SDs. The Kolmogorov-Smirnov test was used to test the assumption of Gaussian distribution. Pearson's correlation was used to measure associations between SI and CVD risk factors. Hierarchical multiple regression analysis adjusting for age was conducted to identify associations between the independent variables $\left(\mathrm{VO}_{2}\right.$ peak, $\mathrm{SBP}, \mathrm{BMI}$, physical activity, RHR and WC) and the dependent variable (SI). The independent variables were separated into two blocks: age in one block, and $\mathrm{VO}_{2}$ peak, SBP, BMI, physical activity, RHR and WC in the other. Variance of inflation factors was calculated to investigate collinearity in any of the analyses. A significance level of $p \leq 0.05$ was used.

\section{Ethical considerations}

Ethical clearance was obtained from the University of Zululand Research Ethics Committee (ref. no. UZREC171110-030). All participants and parents gave their informed consent before commencement of the study. In addition, permission to conduct the study was also obtained from the KwaZulu-Natal Department of Education (ref. no. 2/4/8/815). The study was conducted in accordance with the World Medical Association Declaration of Helsinki on ethical principles involving the use of human subjects in medical research. ${ }^{[19]}$

\section{Results}

Of the 59 participants, 17 were male (29\%) and 42 female (71\%). Regression coefficients (Table 1) showed that a large proportion of the variation in SI among male participants was explained by age $(\beta=0.52 ; p=0.03)$ and $\mathrm{VO}_{2}$ peak $(\beta=-0.41 ; p=0.39)$. In female participants, $\mathrm{VO}_{2}$ peak $(\beta=-0.38 ; p=0.21)$ and $\operatorname{RHR}(\beta=0.26 ; p=0.18)$ explained the largest proportion of the variation in SI. When results were combined across the gender groups (Table 2), the largest proportion of the variation in SI was explained by age $(\beta=0.26$; $p=0.04)$, $\operatorname{RHR}(\beta=0.24 ; p=0.09)$ and $\mathrm{VO}_{2}$ peak $(\beta=0.24 ; p=0.32)$.

Among male participants, SI was found to be significantly positively correlated with age $(r=0.52 ; p=0.03)$ and significantly negatively correlated with $\mathrm{VO}_{2}$ peak $(r=-0.53 ; p=0.03)$. Following regression analysis, the association between age $\left(r^{2}=0.27 ; p=0.03\right)$ and SI

Table 1. Baseline characteristics of male and female study participants

\begin{tabular}{|c|c|c|c|c|}
\hline \multirow[b]{2}{*}{ Variable } & \multicolumn{2}{|c|}{ Male $(n=17)$} & \multicolumn{2}{|c|}{ Female $(n=42)$} \\
\hline & Mean (SD) & $\beta$ (p-value $)$ & Mean (SD) & $\beta$ (p-value $)$ \\
\hline $\mathrm{SI}\left(\mathrm{ms}^{-1}\right)$ & $5.40(0.62)$ & NA & $5.53(0.58)$ & NA \\
\hline BMI $z$-score & $1.13(1.39)$ & $0.18(0.61)$ & $0.72(1.17)$ & $0.10(0.69)$ \\
\hline RHR (bpm) & $79.11(6.99)$ & $-0.06(0.88)$ & $80.66(7.54)$ & $0.26(0.18)$ \\
\hline Physical activity & $2.46(0.29)$ & $-0.28(0.34)$ & $2.58(0.56)$ & $0.02(0.87)$ \\
\hline $\mathrm{WC}(\mathrm{cm})$ & $41.85(24.51)$ & $-0.15(0.70)$ & $55.98(18.16)$ & $-0.04(0.84)$ \\
\hline SBP (z-score) & $1.51(1.02)$ & $0.25(0.51)$ & $0.84(0.78)$ & $-0.17(0.31)$ \\
\hline $\mathrm{VO}_{2}$ peak $\left(\mathrm{mL} \cdot \mathrm{kg}^{-1} \mathrm{~min}^{-1}\right)$ & $41.44(2.11)$ & $-0.41(0.39)$ & $40.73(4.00)$ & $-0.38(0.21)$ \\
\hline
\end{tabular}


Table 2. Baseline characteristics of study participants combined across gender groups $(N=59)$

\begin{tabular}{lll}
\hline Variable & Mean $(\mathrm{SD})$ & $\beta(p$-value $)$ \\
\hline SI $\left(\mathrm{ms}^{-1}\right)$ & $5.5(0.59)$ & $\mathrm{N} / \mathrm{A}$ \\
Age $($ years $)$ & $11.15(1.4)$ & $0.26(0.04)$ \\
BMI $z$-score & $0.78(1.42)$ & $0.09(0.58)$ \\
RHR $($ bpm $)$ & $80(7.37)$ & $0.24(0.09)$ \\
Physical activity & $2.51(0.41)$ & $-0.03(0.79)$ \\
WC $(\mathrm{cm})$ & $51.91(20.10)$ & $-0.02(0.88)$ \\
SBP $(z$-score $)$ & $1.05(0.89)$ & $-0.14(0.29)$ \\
$\mathrm{VO}_{2}$ peak $\left(\mathrm{mL} \cdot \mathrm{kg}^{-1} \mathrm{~min}^{-1}\right)$ & $40.93(3.55)$ & $0.24(0.32)$
\end{tabular}

$\mathrm{SI}=$ stiffness index BMI = body mass index RHR = resting heart rate; $\mathrm{bpm}=$ beats per minute; $\mathrm{WC}=$ waist circumference; $\mathrm{SBP}=$ systolic blood pressure;

$\mathrm{VO}_{2}$ peak = peak oxygen consumption.

remained significantly independent. No significant correlations were found for any of the variables with SI among female participants. When means were combined across the gender groups (Table 2), age $(r=0.27 ; p=0.04)$ and RHR $(r=0.26 ; p=0.05)$ demonstrated significant positive correlations with SI. Following regression analysis, the association with SI remained significantly independent for both age $\left(r^{2}=0.07 ; p=0.04\right)$ and RHR $\left(r^{2}=0.15 ; p=0.02\right)$.

\section{Discussion}

This study is the first to report on the associations between conventional CVD risk factors and arterial stiffness in black South African children. The primary findings indicate that arterial stiffness was independently associated with age in male participants, whereas none of the assessed variables showed a correlation with arterial stiffness in female participants. When results were combined across the two gender groups, SI, as an indication of arterial stiffness, was found to be independently associated with both age and RHR.

Studies from Brazil and Canada have reported associations between conventional CVD risk factors and arterial stiffness in children, ${ }^{[5,20]}$ although the cross-sectional study of 485 Canadian children (aged 12 - 14 years) found no significant associations between arterial stiffness, conventional CVD risk factors and physical activity levels. ${ }^{[20]}$ The authors concluded that associations between arterial stiffness and physical activity may appear in children only when activity levels are at either end of the physical activity continuum. ${ }^{[20]}$ This is in line with findings from our study, in which participants' physical activity levels were observed as moderate (mean (SD) $2.51(0.41)$ ) and without significant association with SI.

The mentioned study among 231 Brazilian children (aged 9 10 years) found significant associations between SI and BMI. ${ }^{[5]}$ This differs from our findings, which showed the only CVD risk factors associated with SI to be RHR and age.

The SI values reported by Walker et al. ${ }^{[20]}$ are higher than those found in our study. The mean (and associated SD) values for SI in boys $\left(5.40(0.62) \mathrm{ms}^{-1}\right)$ and girls $\left(5.53(0.58) \mathrm{ms}^{-1}\right)$ in our study compare favourably with the mean values reported for carotid radial pulse wave velocity in their study $\left(7.63 \mathrm{~ms}^{-1}\right.$ and $7.48 \mathrm{~ms}^{-1}$ for boys and girls, respectively). Combined mean (and associated $\mathrm{SD}$ ) values for SI found in our study $\left(5.5(0.59) \mathrm{ms}^{-1}\right)$ were similar to those reported from the mentioned study among Brazilian children (5.3 $\left.(0.52) \mathrm{ms}^{-1}\right) .{ }^{[5]}$ The higher SI values reported by Walker et al. ${ }^{[20]}$ could be attributed to the observation that SI increases with age.

Age could be an important variable when studying arterial stiffness, but for a deeper understanding it should be assessed in conjunction with growth and maturation, given that body height at the transition from childhood to adolescence has been reported to affect arterial stiffness. ${ }^{[21]}$

Associations between RHR and arterial stiffness in children have not been well documented in literature. However, findings on normotensive adults suggest that a higher RHR is independently associated with increased arterial stiffness. ${ }^{[22]}$ In our study, RHR and arterial stiffness appear to be positively associated if the results from the two gender groups are combined, with a dependent association with $\mathrm{VO}_{2}$ peak seen among boys. These results suggest that fitness levels may have an important role in the regulation of vascular health in children. Indeed, cardioprotective benefits of $\mathrm{VO}_{2}$ peak have been documented and include the capacity for vessel-wall regeneration and angiogenesis. ${ }^{[23]}$

\section{Study limitations}

This study did not consider genetic, metabolic, environmental, socioeconomic or maturation-related influences on arterial stiffness. The lack of pubertal staging, mixed ages of the participants and the fairly small sample size may be considered further limitations.

\section{Conclusion}

The present study suggests that age and RHR are key predictors of arterial stiffness in black SA children. Furthermore, different gender associations with SI highlight the need for gender-specific CVD risk screening in this population.

\section{Declaration. None.}

Acknowledgements. None.

Author contributions. AvB was responsible for the study concept and design. All authors contributed to data analysis and interpretation, and drafting the manuscript, critically reviewing its intellectual content and final approval of the content.

Funding. None.

Conflicts of interest. None.

1. Naghavi M, Wang H, Lozano R, et al. Global, regional, and national age-sex specific all-cause and cause-specific mortality for 240 causes of death, 19902013: A systematic analysis for the Global Burden of Disease Study 2013. Lancet 2015;385(9963):117-171. https://doi.org/10.1016/S0140-6736(14)61682-2

2. Després JP, Lemieux I, Bergeron J, et al. Abdominal obesity and the metabolic syndrome: Contribution to global cardiometabolic risk. Arterioscler Thromb Vasc Biol 2008;28(6):1039-1049. https://doi.org/10.1161/ ATVBAHA.107.159228

3. Hong YM. Atherosclerotic cardiovascular disease beginning in childhood. Korean Circ J 2010;40(1):1-9. https://doi.org/10.4070/kcj.2010.40.1.1

4. Kim H-L, Kim S-H. Pulse wave velocity in atherosclerosis. Front Cardiovasc Med 2019;6:41. https://doi.org/10.3389/fcvm.2019.00041

5. Batista MS, Mill JG, Pereira TSS, Fernandes CDR, Molina MCB. Factors associated with arterial stiffness in children aged 9-10 years. Rev Saude Publica 2015;49:23. https://doi.org/10.1590/s0034-8910.2015049005425

6. Reed KE, Warburton DE, Lewanczuk RZ, et al. Arterial compliance in young children: The role of aerobic fitness. Eur J Cardiovasc Prev Rehabil 2005;12:492497. https://doi.org/10.1097/01.hjr.0000176509.84165.3d

7. Urbina EM, Gao Z, Khoury PR, Martin LJ, Dolan LM. Insulin resistance and arterial stiffness in healthy adolescents and young adults. Diabetologia 2012;55(3):625-631. https://doi.org/10.1007/s00125-011-2412-1

8. Putarek K, Banfic L, Pasalic M, Krnic N, Uroic AS, Putarek NR. Arterial stiffness as a measure of cardiovascular risk in obese adolescents and adolescents with diabetes type 1. J Pediatric Endocrinol Metab 2018;31(12):1315-1323. https:// doi.org/10.1515/jpem-2018-0137

9. Gerber M, Müller I, Walter C, et al. Physical activity and dual disease burden among South African primary schoolchildren from disadvantaged neighbourhoods. Prev Med 2018;112:104-110. https://doi.org/10.1016/j. ypmed.2018.04.001

10. Mokwatsi GG, Schutte AE, Kruger R. Ethnic differences regarding arterial stiffness of 6-8-year-old black and white boys. J Hypertens 2017;35(5):960-967. https://doi.org/10.1097/hjh.0000000000001267 
11. Kowalski KC, Crocker PRE, Donen RM. The Physical Activity Questionnaire for Older Children (PAQ-C) and Adolescents (PAQ-A) Manual. Saskatoon: University of Saskatchewan, 2004.

12. World Health Organization. Waist circumference and waist-hip ratio: Report of a WHO expert consultation, Geneva, 8-11 December 2008. Geneva: WHO, 2011. http://www.who.int/nutrition/publications/obesity/WHO_ report_waistcircumference_and_waisthip_ratio/en/.

13. National Center for Health Statistics. The Third National Health and Nutrition Examination Survey (NHANES III 1988-94). Atlanta: Centers for Disease Control and Prevention, 2005.

14. National High Blood Pressure Education Program Working Group on High Blood Pressure in Children and Adolescents. The fourth report on the diagnosis, evaluation, and treatment of high blood pressure in children and adolescents. Pediatrics 2004;114(2 Suppl 4th Report):555-576.

15. Léger LA, Mercier M, Gadoury C, Lambert J. The multistage 20 metre shuttle run test for aerobic fitness. J Sports Science 1988;6(2):93-101. https://doi. org/10.1080/02640418808729800

16. Léger L, Lambert L. A maximal multistage 20-m shuttle run test to predict VO2 max. Eur J Appl Physiol Occup Physiolo 1982;49(1):1-12. https://doi. org/10.1007/bf00428958

17. Veijalainen A, Tompuri T, Lakka H-M, Laitinen T, Lakka TA. Reproducibility of pulse contour analysis in children before and after maximal exercise stress test: The Physical Activity and Nutrition in Children (PANIC) study. Clin Physiol Funct Imaging 2011;31:132-138. https://doi.org/10.1111/j.1475097x.2010.00989.x
18. Veijalainen A, Tompuri T, Laitinen T, et al. Metabolic risk factors are associated with stiffness index, reflection index and finger skin temperature in children. Physical Activity and Nutrition in Children (PANIC) study. Circ J 2013;77(5):12811288. https://doi.org/10.1253/circj.cj-12-0704

19. World Medical Association. World Medical Association Declaration of Helsinki: Ethical principles for medical research involving human subjects. JAMA 2013;310(20):2191-2194.

20. Walker DJ, MacIntosh A, Kozyrskyj A, Becker A, McGavock J. The associations between cardiovascular risk factors, physical activity, and arterial stiffness in youth J Phys Act Health 2013;10(2):198-204. https://doi.org/10.1123/jpah.10.2.198

21. Manco M, Nobili V, Alisi A, Panera N, Handberg A. Arterial stiffness, thickness and association to suitable novel markers of risk at the origin of cardiovascular disease in obese children. Int J Med Sci 2017;14(8):711-720. https://doi.org/10.7150/ ijms. 20126

22. Logan JG, Kim S-S. Resting heart rate and aortic stiffness in normotensive adults. Korean Circ J 2016;46(6):834-840. https://doi.org/10.4070/kcj.2016.46.6.834

23. Fiuza-Luces C, Garatachea N, Berger NA, Lucia A. Exercise is the real polypill. Physiology (Bethesda) 2013;28(5):330-358. https://doi.org/10.1152/ physiol.00019.2013

Accepted 19 June 2020 